Article

\title{
Summertime Urban Mixing Layer Height over Sofia, Bulgaria
}

\author{
Ventsislav Danchovski (D) \\ Department of Meteorology and Geophysics, Faculty of Physics, Sofia University, Sofia 1164, Bulgaria; \\ danchovski@phys.uni-sofia.bg; Tel.: +359-2-8161-413
}

Received: 7 November 2018; Accepted: 9 January 2019; Published: 17 January 2019

\begin{abstract}
Mixing layer height (MLH) is a crucial parameter for air quality modelling that is still not routinely measured. Common methods for MLH determination use atmospheric profiles recorded by radiosonde but this process suffers from coarse temporal resolution since the balloon is usually launched only twice a day. Recently, cheap ceilometers are gaining popularity in the retrieval of MLH diurnal evolution based on aerosol profiles. This study presents a comparison between proprietary (Jenoptik) and freely available (STRAT) algorithms to retrieve MLH diurnal cycle over an urban area. The comparison was conducted in the summer season when MLH is above the full overlapping height of the ceilometer in order to minimize negative impact of the biaxial LiDAR's drawback. Moreover, fogs or very low clouds which can deteriorate the ceilometer retrieval accuracy are very unlikely to be present in summer. The MLHs determined from the ceilometer were verified against those measured from the radiosonde, which were estimated using the parcel, lapse rate, and Richardson methods (the Richardson method was used as a reference in this study). We found that the STRAT and Jenoptik methods gave lower MLH values than radiosonde with an underestimation of about $150 \mathrm{~m}$ and $650 \mathrm{~m}$, respectively. Additionally, STRAT showed some potential in tracking the MLH diurnal evolution, especially during the day. A daily MLH maximum of about $2000 \mathrm{~m}$ was found in the late afternoon (18-19 LT). The Jenoptik algorithm showed comparable results to the STRAT algorithm during the night (although both methods sometimes misleadingly reported residual or advected layers as the mixing layer (ML)). During the morning transition the Jenoptik algorithm outperformed STRAT, which suffers from abrupt changes in MLH due to integrated layer attribution. However, daytime performance of Jenoptik was worse, especially in the afternoon when the algorithm often cannot estimate any MLH (in the period 13-16 LT the method reports MLHs in only $15-30 \%$ of all cases). This makes day-to-day tracing of MLH diurnal evolution virtually impracticable. This problem is possibly due to its early version (JO-CloVis $8.80,2009$ ) and issues with real-time processing of a single profile combined with the low signal-to-noise ratio of the ceilometer. Both LiDAR-based algorithms have trouble in the evening transition since they rely on aerosol signature which is more affected by the mixing processes in the past hours than the current turbulent mixing.
\end{abstract}

Keywords: mixing layer; urban area; ceilometer; radiosonde

PACS: 01.30.-y; 01.30.Ww; 01.30.Xx

\section{Introduction}

The effect of air quality on human health is a serious problem, especially in densely populated areas. Hence, a lot of effort is being made to better understand the processes controlling pollution levels, particularly in numerical modelling. Key input parameters of these models are meteorological variables, which are needed to be identified in order to calculate the production, diffusion, transport and scavenging of atmospheric pollutants. These harmful substances are dispersed vertically within 
the mixing layer (ML) due to its inherent turbulence. According to Seibert et al. [1], ML is "... the layer adjacent to the ground over which pollutants or any constituents emitted within this layer or entrained into it become vertically dispersed by convection or mechanical turbulence within a time scale of about an hour". However, one should bear in mind that there are situations when time-scales of the dominant processes (such as diabatic processes like radiative cooling in the evening transition, or unsteadiness of pressure gradients, or intermittent turbulence due to breaking gravity waves, just to name a few) are much longer so that the ML is unsteady [2]. Obviously, near-ground pollution levels will depend on the mixing layer height (MLH) since it constrains the dispersion volume. Thus, the MLH is vitally important to be identified especially in urban areas where pollution sources and inhabitants are much greater [3-10]. Moreover, urban MLH can be characterized by enormous temporal and spatial variability due to inhomogeneity in surface roughness and heating in cities [11]. Therefore, MLH is worthwhile to be continuously monitored and also compared with parametrizations in numerical weather and/or pollution prediction models [12-14].

Despite its importance, MLH is not a part of routine measurements. Furthermore, because it is associated with the spatial distribution of turbulence, we need turbulence profiles to determine MLH. Consequently, TKE (turbulent kinetic energy)-based criteria (MLH is marked by the level where TKE drops below a predefined threshold) are often used in numerical models with turbulence closure of order 1.5 or higher for MLH determination [1,15]. Moreover, profiles of the TKE and its dissipation rate can be measured by remote sensing instruments $[16,17]$. Therefore, Doppler LiDARs [18] and sodars $[19,20]$ can serve as "turbulence profilers" but the former are quite expensive and the latter have limited vertical range. Fortunately, vertical profiles of non-reactive scalar meteorological variables should be nearly constant with height within a well-mixed boundary layer [21], so we can detect the MLH by looking for abrupt changes in the uniformly distributed profiles of these tracers [22,23].

Regardless of the wide variety of remote sensing methods, the most used instrument for MLH detection is the radiosonde, which is still used as a reference. The derivation of the MLH from the radiosonde profiles of the atmospheric temperature, humidity, and wind dates back to 1960s [24]. Moreover, these radiosonde-based methods are still used independently [25] or as a reference for validating MLH measurements from remote sensing instruments [26]. However, the radiosonde also has some drawbacks as it measures atmospheric properties along its flight, which is slant instead of vertical, due to horizontal wind. Therefore, the radiosonde profiles do not coincide with rising thermal or vertical profiles derived from the remote sensing instruments. Additionally, the radiosondes' main limitation is their coarse temporal resolution since they are usually launched no more than twice a day.

The necessity of continuous MLH monitoring can be met by operating ground-based remote sensing instruments. A comprehensive review of existing techniques for MLH determination through ground-based remote sensing instruments, along with their advantages and limitations, can be found in Wiegner et al. [27] and Emeis et al. [28]. It is worthwhile to note that individual disadvantages of each instrument in the MLH diurnal cycle determination can be overcome if apparatuses are used together [29].

One should note that relying on ground-based remote sensing instruments in MLH estimation cannot provide good spatial representativeness, especially over areas with non-homogeneous land-use and/or complex topography. Fortunately, this lack of information can be filled if space-based remote sensing instruments are used. Among them are the Cloud-Aerosol LiDAR with Orthogonal Polarization (CALIOP) [30] and the Moderate Resolution Imaging Spectroradiometer (MODIS) [31], which are the most used for determination of the atmospheric boundary layer height over continents and oceans [32-35]. The radio occultation method based on global position system signals can provide vertical profiles of the refractivity index that can be used in MLH retrieval [36,37].

In recent years, laser-based remote sensing instruments, especially automatic LiDARs and ceilometers (ALC), have become more affordable and widely used in the field of atmospheric research, particularly for MLH determination [38-45]. We should also note the considerable efforts made in the COST Action ES 1303 TOPROF [46] which provides standards for calibrated profiles of the aerosols, 
winds, temperature, and humidity to fill the observational gap in the lower troposphere. These quality controlled observations are delivered in near real-time through the EUMETNET Composite Observing System (EUCOS) network E-PROFILE [47] to the national weather services in order to improve numerical weather prediction.

Different LiDAR-based methods for MLH retrieval from the range corrected signal are summarized in Haeffelin et al. [48]. These methods are the basis of many proprietary [49,50] and in-house [51-54] algorithms explicitly designed for MLH retrieval from ceilometers' data. Possible performance improvement of these LiDAR-based techniques can be achieved by monitoring diurnal variations in Radon-222 [55] or it can be used alone to evaluate MLH [56].

The objectives of the present study are to evaluate the performance of a proprietary algorithm as well as a popular, freely available algorithm in detecting of MLH from ceilometer data over an urban area. Both methods are evaluated against MLHs retrieved using radiosonde profiles as a reference. The structure and evolution of the mixing layer over Sofia in summertime is also discussed. To highlight the advantages and disadvantages of both algorithms, an analysis was performed in the summer when MLH is high enough to minimize the negative effects due to incomplete overlapping in the near-field range of the ceilometer. The paper is organized as follow: measurement sites and specifications of the instruments used for observations, as well as details about the collected data and methods applied to determine the MLH, are in Section 2. Inter-comparison of the three radiosonde-based methods is in Section 3.1. Verification of the MLH retrieved from the ceilometer compared to the MLH measured from the radiosonde is in Section 3.2. Diurnal evolution of the MLH over Sofia derived from the ceilometer data by both the proprietary and the freely available algorithm, as well as a discussion of their main benefits and drawbacks and suggestions for performance improvement, are in Section 3.3. Statistical analysis of the MLH diurnal cycle is discussed in Section 3.4. The article ends with summary of findings.

\section{Data and Methodology}

Sofia is the largest and the most densely populated city in Bulgaria with roughly 1,400,000 inhabitants. The city is located in a valley that is almost fully encircled by mountains; therefore, the micro- and meso-scale processes, as well as the ML dynamics, are heavily influenced by both complex orography and urban territory. To perform our analysis of urban MLH we used 3 months of intensive measurements, from 1 June until 31 August 2015. The data used in this study were obtained from a continuously operating ceilometer, Jenoptik CHM 15k (in 2014, the company G. Lufft Mess- und Regeltechnik GmbH acquired the product segment of ceilometers from Jenoptik and now the ceilometer is known as Lufft CHM 15k), and a balloon sounding launched on a daily basis at 12:00 UTC (14:00 LT).

The CHM15k (firmware version 0.63) is operated by the Department of Meteorology and Geophysics, Sofia University. The ceilometer is situated in the city centre on the territory of the University Astronomical Observatory in the park "Borisova gradina" (Figure 1). The CHM15k is an eye-safe biaxial LiDAR system equipped with an Nd: YAG solid-state near-infra-red laser operating at $1064 \mathrm{~nm}$. It emits pulses with an energy of $8 \mu \mathrm{J}$ and a repetition frequency of 5-7 kHz. The ceilometer provides data with a vertical resolution of $15 \mathrm{~m}$, the maximum height of the signal is $15,000 \mathrm{~m}$ and the temporal resolution is set up to $60 \mathrm{~s}$. As CHM15k is a biaxial LiDAR it suffers from incomplete overlap in the near range since only a small portion of the laser beam gets into the receiver field of view. According to the manufacturer, the overlapping is $\sim 1 \%$ at 15 th bin $(225 \mathrm{~m}), \sim 10 \%$ at 24 th bin $(360 \mathrm{~m}), \sim 50 \%$ at 40 th bin $(600 \mathrm{~m}), \sim 90 \%$ at 57 th bin $(855 \mathrm{~m}), \sim 99 \%$ at 78 th bin $(1170 \mathrm{~m})$ and full overlap is achieved at 120th bin $(1800 \mathrm{~m})$. Further details about the instrument can be found in [57].

The MLH was retrieved from the ceilometer profiles by supposing that aerosol concentration is rapidly adapted to the thermal stratification of the ML and that aerosol loading above the city is not dominated by advection. The manufacturer's software includes a proprietary algorithm for automatically deriving the MLH every minute (software JO-CloVis version 8.80) [58]. Because the Jenoptik algorithm is proprietary not much is known about it. Haeffelin et al. [48] reported that the 
algorithm uses vertical derivatives and wavelet transforms on the range-corrected signal to identify local minima which are used as MLH, however, it is not specified which version is referred to and there is no information on how signal-to-noise ratio is enhanced in the pre-processing. A freely available Structure of the Atmosphere (STRAT) algorithm [52], which is designed for the retrieval of aerosol vertical profiles in the atmospheric boundary layer and free troposphere, is used for comparison. In contrast to the Jenoptik algorithm that is based on vertical gradients of backscatter signal in a single profile, STRAT uses both temporal and vertical gradients $\left(G_{t}\right.$ and $\left.G_{v}\right)$ by using Sobel 2-D derivation operators. The global gradient is calculated as $G=\sqrt{G_{t}^{2}+G_{v}^{2}}$. The edges in backscatter are kept if $G$ is greater than predefined thresholds. Additionally, edges in low signal-to-noise ratio zones are rejected. Finally, minimum (450 m due to overlapping) and maximum (here, $3000 \mathrm{~m}$ during the day and $1500 \mathrm{~m}$ at night are used) allowed heights are applied and three global gradients-the strongest, the second strongest, and the lowest-height-are reported as MLH candidates [48]. The MLH is then determined as the lowest-height candidate at night, during day quality control based on relative change in backscatter around each candidate is performed and the first existing one in the line strongest, second strongest and lowest is selected as MLH [18].

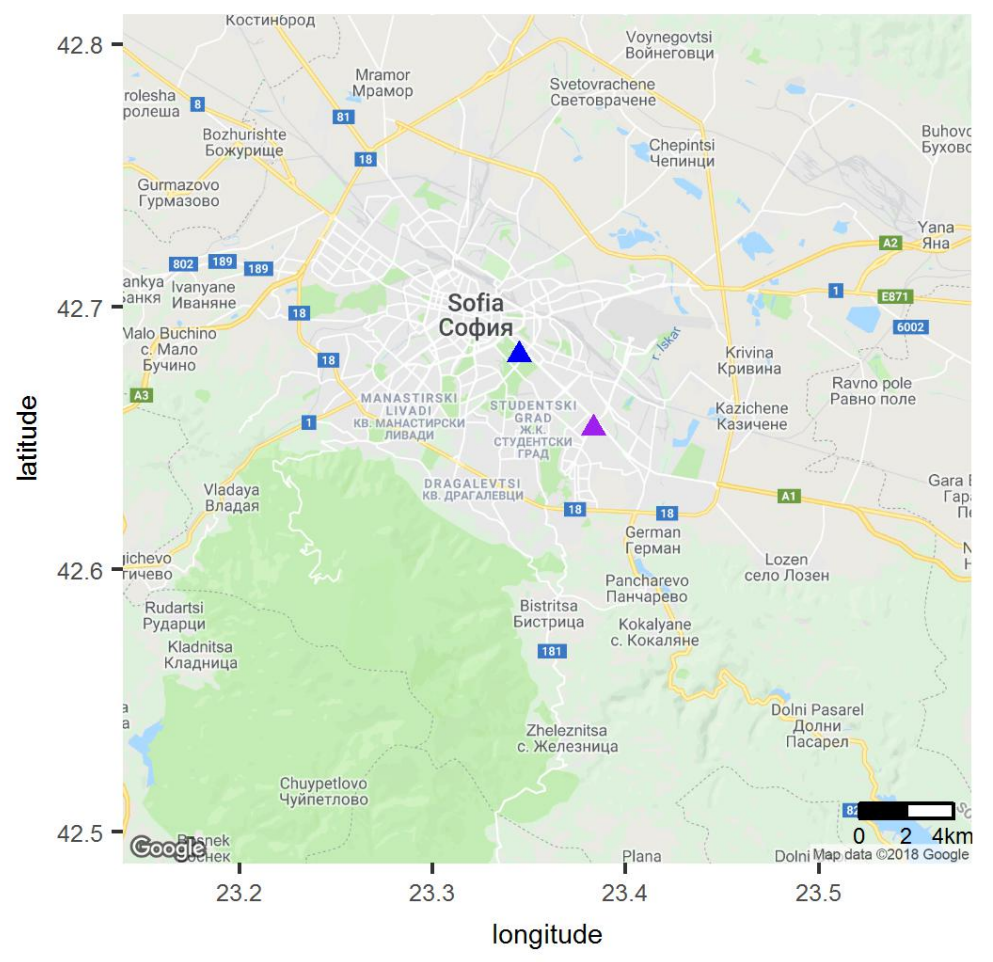

Figure 1. The locations of the ceilometer and the radiosonde indicated by a blue and a purple triangle in the Sofia valley. (Source of the map is Google LLC).

The atmospheric sounding system is the Vaisala's MW41 which is located in the Central Aerological Observatory on the territory of the National Institute of Meteorology and Hydrology, which is about $4.4 \mathrm{~km}$ south-east from the ceilometer (Figure 1). In this study, low resolution radiosonde data are used, which are freely available at Integrated Global Radiosonde Archive (IGRA) [59]. Archived radiosonde data consist of atmospheric parameters recorded at mandatory and significant levels which were used to restore the atmospheric profiles by linear interpolation.

Following de Haij et al. [60], three different MLH detecting algorithms were applied to the radiosonde data. The Bulk Richardson (Ri) method is based on the Richardson number which is the ratio of thermally and mechanically driven turbulence. According to this method, MLH is the level where the bulk Richardson number exceeds predefined threshold values [61-63]. In this study, 
the commonly recommended value of 0.21 was used. It is worth noting that the Ri method is suitable for both convective and stable conditions. In the parcel method [24,64], the MLH is determined by extending dry-adiabatically surface temperature to its intersection point with temperature profile. However, this method provides reliable results only for unstable convective boundary layer as it neglects wind shear effects on vertical mixing. The last method for MLH determination from radiosonde data is the lapse rate method [21,65]. It is based on threshold values of vertical gradients of potential temperature $(\theta)$ and relative humidity (RH). Adhering to de Haij et al. [60], negative gradients of $\mathrm{RH}$ and a gradient of $\theta>2 \mathrm{~K} / \mathrm{km}$ were used as the basis for this study. As the selected critical value of potential temperature gradient is more or less subjectively chosen, the performance of lapse rate values of $0.5,1,1.5,2.5,3,3.5$, and $4 \mathrm{~K} / \mathrm{km}$ was also tested.

As main synoptic-scale systems are associated with the suppression or stimulation of parcel ascending, it is interesting to examine their role on mixing layer height [66]. Therefore, the difference $(\Delta p)$ of surface layer atmospheric pressure $(p)$ and its smoothed value $\left(p_{\text {smooth }}\right.$, which is obtained by low pass filter with cut-off 6 days) is calculated by Equation (1). Then $\Delta p$ is standardized by Equation (2), i.e., the $\Delta p$ is rescaled to have a mean of zero (subtraction of the mean value $\overline{\Delta p}$ ) and a standard deviation of one (division by the standard deviation $\sigma_{\Delta p}$ ).

$$
\begin{gathered}
\Delta p=p-p_{\text {smooth }} \\
\Delta p_{\text {std }}=\frac{\Delta p-\overline{\Delta p}}{\sigma_{\Delta p}}
\end{gathered}
$$

Finally, the atmospheric pressure (atm.press) is classified as "Low" if $\Delta p_{\text {std }}$ is smaller than -0.5 while it is marked as "High" if $\Delta p_{s t d}$ is higher than 0.5 . If the $\Delta p_{s t d}$ values are greater than -0.5 but less than 0.5 , atmospheric pressure is marked as "Normal".

\section{Results and Discussions}

\subsection{Inter-Comparison of Radiosonde-Based MLH Retrieval Methods}

The three aforementioned radiosonde-based algorithms-Richardson, parcel and lapse-ratewere applied on the dataset for a total of 92 days (for 28 days the atmospheric pressure was "High", for 43 "Normal", and for 21 "Low"). MLH values were successfully estimated at 92, 92, and 81 days, respectively. The estimated MLHs were then compared against one another on Figure 2. The perfect correlation between the Richardson and parcel method indicates that in summer at 14:00 LT (12:00 UTC) the urban mixing layer over Sofia is dominated by thermally driven turbulence. It is a fairly expected result since the study period took place in summer and radiosonde launching occurred in the early afternoon. The box-plot shows that slightly higher MLH values are related to prevailing low atmospheric pressure and that when atmospheric pressure is marked as normal or high, MLHs are slightly decreased; however, the observed difference is not statistically significant (Wilcoxon-Mann-Whitney test with a significance level of $5 \%$ was performed).

The lapse rate method shows worse alignment with the Richardson and parcel methods, therefore, we tested how a threshold value of vertical gradient $\theta$ influences concurrence with the other two approaches. We found that lapse rate values of $1,1.5$ and $2 \mathrm{~K} / \mathrm{km}$ perform similarly and Pearson correlation coefficients with respect to the Ri method are about 0.89. However, the correlation diminishes if smaller or higher threshold values are used. It is also worth mentioning that a negative vertical gradient of the relative humidity is not changed because it agrees with the mixing layer conception (the Earth's surface is the water vapour source and free atmosphere is low in humidity, so the humidity gradient should be negative at MLH). Keeping in mind that the Ri method incorporates both mechanical and buoyancy production of turbulent mixing we choose it as a reference in the following analysis. Performance of the parcel and lapse rate methods using the set of critical values mentioned above were evaluated against the Richardson method and is summarised in Table 1. 
(a)

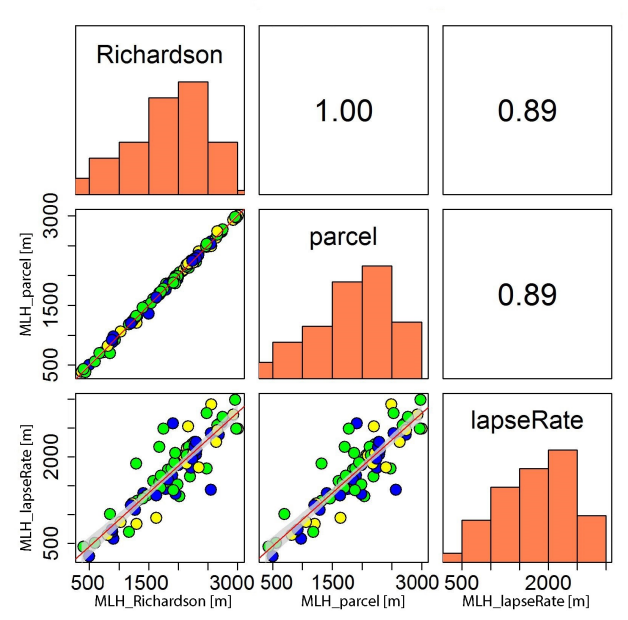

(b)

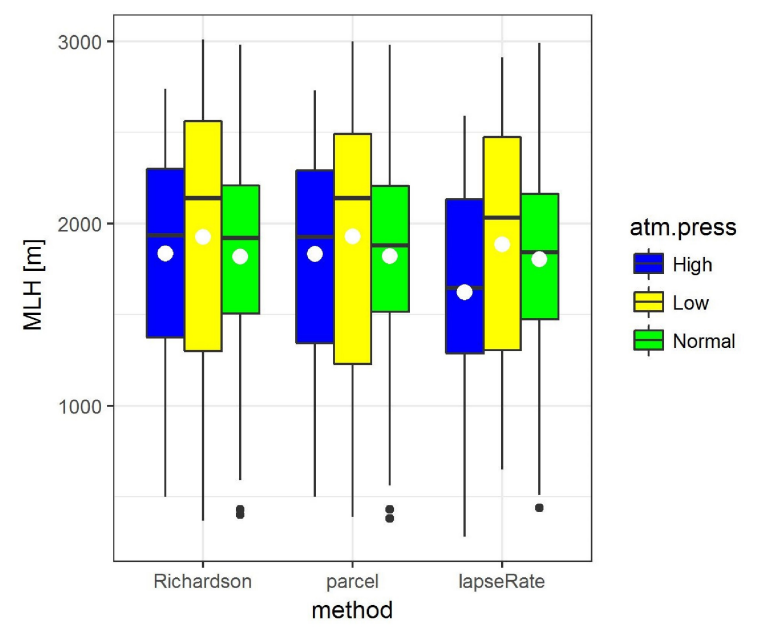

Figure 2. Inter-comparison of the three radiosonde-based MLH methods. The correlation matrix (a) shows correlation coefficients in the upper-right triangle, the diagonal shows a histogram of each method, and the lower-left triangle shows scatter-plots and linear regression lines with corresponding $95 \%$ confidence intervals. The box and whisker plot (in the style of Tukey) is on plot (b). The box lines correspond to the 25, 50 and 75 percentiles. The lower and upper whiskers represent the lowest values still within 1.5 IQR (inter-quantile range) of the lower quartile, and the highest values still within 1.5 IQR of the upper quartile. The data beyond the end of the whiskers signify outliers and are plotted as black dots. White dots indicate mean values. In both figures, atmospheric pressure is color-coded as "High" (blue), "Low" (yellow), “Normal” (green).

Table 1. Skill scores (MD—mean deviation; RMSD—root-mean-square deviation, $\mathrm{r}$-Pearson correlation coefficient, slope-linear regression slope, intercept-linear regression intercept) of parcel and lapse rate methods compared against the Richardson method as a reference in the MLH determination.

\begin{tabular}{cccccc}
\hline Method & MD [m] & RMSD [m] & r & Slope & Intercept [m] \\
\hline parcel & 1 & 37 & 1.00 & 0.99 & 11 \\
lapse rate $0.5 \mathrm{~K} / \mathrm{km}$ & -215 & 396 & 0.85 & 0.82 & 520 \\
lapse rate $1.0 \mathrm{~K} / \mathrm{km}$ & -200 & 351 & 0.89 & 0.88 & 402 \\
lapse rate $1.5 \mathrm{~K} / \mathrm{km}$ & -194 & 342 & 0.89 & 0.89 & 388 \\
lapse rate $2.0 \mathrm{~K} / \mathrm{km}$ & -153 & 330 & 0.89 & 0.85 & 417 \\
lapse rate $2.5 \mathrm{~K} / \mathrm{km}$ & -87 & 403 & 0.81 & 0.75 & 554 \\
lapse rate $3.0 \mathrm{~K} / \mathrm{km}$ & -40 & 431 & 0.78 & 0.70 & 601 \\
lapse rate $3.5 \mathrm{~K} / \mathrm{km}$ & 39 & 493 & 0.75 & 0.61 & 719 \\
lapse rate $4.0 \mathrm{~K} / \mathrm{km}$ & 106 & 543 & 0.73 & 0.57 & 773 \\
\hline
\end{tabular}

\subsection{Inter-Comparison of MLHs Derived from Ceilometer and Radiosonde Data}

MLHs calculated from radiosonde data are often used for reference since they are based on the thermodynamic structure of the lowest atmosphere that directly reflects changes in the surface forcing. However, since routine balloon launching usually occurs only twice a day so it does not allow for MLH diurnal evolution to be tracked. Low-cost ceilometers that provide backscatter power profiles are a tempting alternative because they operate continuously.

To evaluate the overall performance of the ceilometer-based methods in the MLH determination, the calculated values are compared against the Richardson method estimates from the radiosonde data. Since the radiosonde in Sofia is launched once a day at 12:00 UTC (14:00 LT), the ceilometer-retrieved MLHs from within a $20 \mathrm{~min}$ timespan are averaged and used in the comparison. After this procedure the size of the STRAT's datasets at "High", "Normal" and "Low" atmospheric pressure is reduced to $18(64 \%), 24(56 \%)$ and 10 (48\%) days, respectively. The Jenoptik algorithm successfully estimates 
MLHs in 13 (46\%), 17 (40\%) and 11 (52\%) days at "High", "Normal" and "Low" atmospheric pressure, respectively. In other words, both ceilometer-based algorithms cannot estimate MLHs in about half of the days with "Low" atmospheric pressure. The percentage of the Jenoptik-retrieved MLHs becomes even lower at "Normal" and "High" pressure, while the performance of STRAT is slightly increased. The left and right panels of Figure 3 show a correlation matrix and box and whiskers plots of the MLH determined by STRAT, Jenoptik and Ri methods at different atmospheric pressures. It is evident that both LiDAR-based algorithms tend to underestimate MLH compared to radiosonde (Richardson). We should bear in mind that MLH estimation from the ceilometer and the radiosonde data rely on different tracers, which may contribute to the observed discrepancy. When optically thick clouds or rain are presented the backscatter signal can be strong enough to saturate the ceilometers receiver so the cloud base or somewhere under the cloud within the rain column is reported as the MLH. To prove the hypothesis, the data was spited to rainy (if nonzero ceilometer's precipitation index is registered from 11:20 to 11:40 UTC) and dry cases. The analysis showed that the difference between Ri and STRAT, and between Ri and Jenoptik are statistically non-significant (t-test with a significant level of 0.05 is performed) in rainy days. In the rest of the days the Ri method reports about $180 \mathrm{~m}(750 \mathrm{~m})$ higher MLH than STRAT (Jenoptik) and the results are statistically significant. Additionally the role of low clouds was tested. In days with low clouds (if cloud base height is $<1500 \mathrm{~m}$ ) the difference between $\mathrm{Ri}$ and STRAT and between Ri and Jenoptik are evaluated as a statistically non-significant. In the rest of the days radiosonde estimates are $212 \mathrm{~m}$ and $493 \mathrm{~m}$ higher than STRAT and Jenoptik respectively and t-test showed that both results are statistically significant. The observed underestimation of the MLH by the ceilometer could be attributed to the difference in land surface type. The ceilometer is situated in the park (while the radiosonde is in a built-up area) so one can expect that some of the solar energy is consumed during evapotranspiration; therefore the rest of the energy that would produce the thermally driven turbulence, and thus MLH raising, is reduced. To prove this, the number of consecutive days with no precipitation (ceilometer's precipitation index is used for the classification) are used to split the data into categories. It was found that the difference between Ri and STRAT methods (the Jenoptik is not included since it shows significant deviation from the Richardson method, see Figure 3) increases with the number of consecutive droughty days, which is supposed to be a result of the lack of available water for evaporation in a built-up zone. Additionally, if the drought period is long, MLH becomes higher and the ceilometer-based method experiences difficulties that are supposed to be a result of diminished backscatter due to the increased volume for aerosol dispersion (Figure 4).

(a)

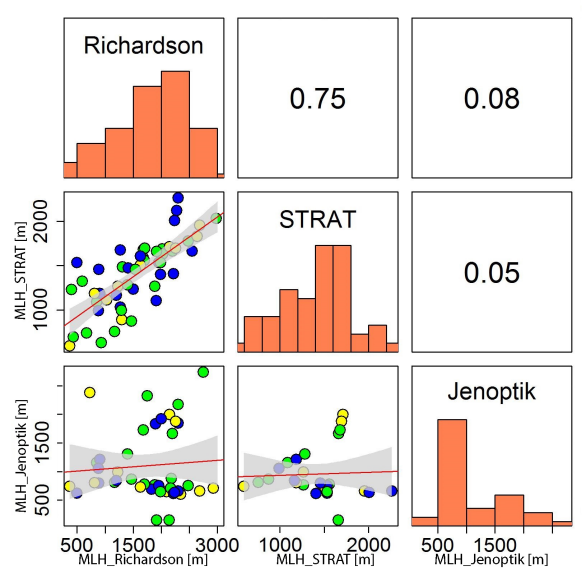

(b)

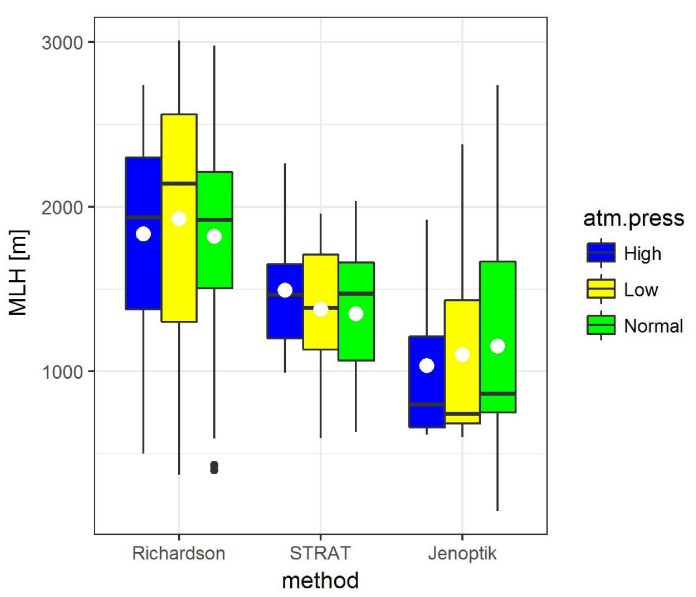

Figure 3. A correlation matrix (a) and Tukey's box and whiskers plot (b) of radiosonde-(Richardson) and LiDAR-based (STRAT and Jenoptik) algorithms for MLH detection. Conventions are the same as in Figure 2. 


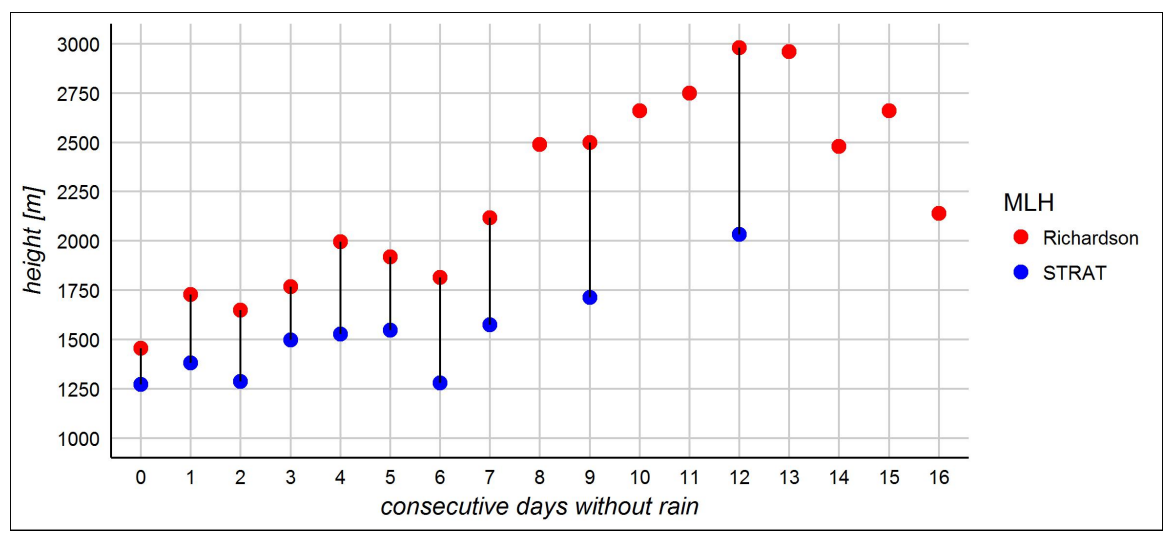

Figure 4. The dependence of drought duration (in number of dry days) on the mean MLH determined by Richardson and STRAT methods.

Skill scores of LiDAR-based algorithms against the Ri method are listed in Table 2. It can be seen that the average underestimation of MLH by STRAT and Jenoptik is $\sim 160 \mathrm{~m}$ and $\sim 660 \mathrm{~m}$ respectively. The STRAT-estimated values of MLH are reasonably comparable with those retrieved from radiosonde profiles, but Jenoptik's performance is quite unpromising and needs further clarification.

Table 2. Skill scores (MD—mean deviation; RMSD—root-mean-square deviation, r-Pearson correlation coefficient, slope-linear regression slope, intercept-linear regression intercept ) of aerosol-based algorithms (Jenoptik and STRAT) compared against the Richardson method as a reference in the MLH determination.

\begin{tabular}{cccccc}
\hline Method & MD [m] & RMSD [m] & r & Slope & Intercept [m] \\
\hline Jenoptik & -665 & 1086 & 0.08 & 0.0 .7 & 970 \\
STRAT & -162 & 467 & 0.75 & 0.45 & 701 \\
\hline
\end{tabular}

\subsection{Diurnal Evolution of the MLH Determined by the Ceilometer-A Case Study}

To elucidate the above-mentioned ceilometer's capacity to track the MLH diurnal cycle, a case study is first considered. In Figure 5 diurnal evolution of the range-corrected ceilometer signal $\left(\mathrm{PR}^{2}\right)$ on July 24 is presented along with MLHs determined according to STRAT and Jenoptik algorithms. Radiosonde-derived MLH by the Richardson method is also plotted for comparison.

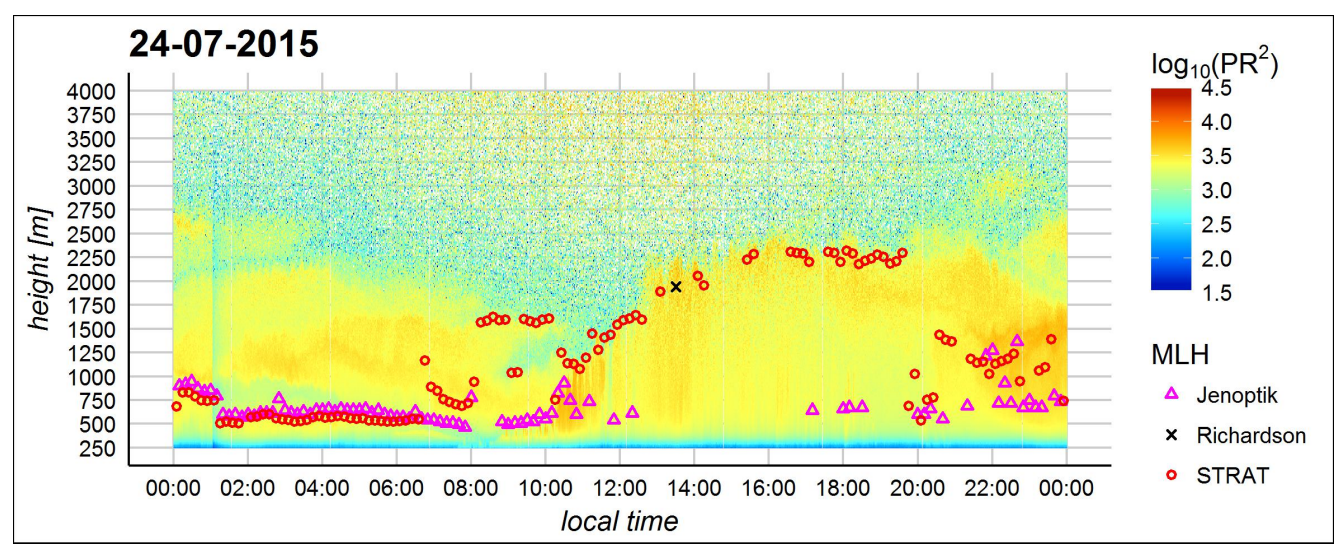

Figure 5. Time-height cross section of the ceilometer's range-corrected backscatter power $\left(\mathrm{PR}^{2}\right.$ in arbitrary units) on 24 July 2015. The MLH retrieved from ceilometer's data by Jenoptik and STRAT algorithms are marked by magenta triangles and red circles, respectively (for clarity, the Jenoptik MLHs are plotted with the same temporal resolution as STRAT-10 min). Radiosonde-based MLH according to the Ri method is presented by black " $x$ " marks. 
As observed, the range corrected ceilometer's signal reveals some characteristic features in the MLH diurnal evolution. The backscatter power within the first $500-700 \mathrm{~m}$ is high in the early hours of the night which can be associated with mechanically mixed aerosols within the nocturnal boundary layer. As seen, the layer was shrinking and at $\sim 8: 00 \mathrm{LT}$ (less than $2 \mathrm{~h}$ after sunrise) it had disappeared. One may expect a new convective layer to be identifiable at that moment but we should keep in mind that the ceilometer has virtually zero overlapping in the first $\sim 200 \mathrm{~m}$ (overlapping is $<1 \%$ ) so that the first signs of the rising thermals are visible at 9:00 LT. Above the nocturnal layer, there is a zone with decreased signal that is capped by a high backscatter layer, which most likely outlines aerosol burden air in the residual layer, or it is a result of advection at that elevation. The ceilometer's signal also depicts the daytime evolution of the MLH with its typical growth due to the solar heating of the surface. After sunrise, thermals start forming and rising due to positive buoyancy. These updrafts produce turbulent mixing so that the diminished vertical backscatter within ML in the afternoon results from an increased volume for aerosol dispersion. An enhanced signal close to the ML top in the afternoon can be attributed to hygroscopic growth of aerosols due to increased relative humidity. As can be seen, MLH reached its maximum $(\sim 2250 \mathrm{~m})$ at $\sim 16: 00 \mathrm{LT}$ and remains almost constant until 19:00 LT. In the evening, the thermals cease to form (in the absence of cold air advection), allowing turbulence to decay in the formerly well mixed layer. A new nocturnal layer starts forming and overhead air associated with the new residual layer becomes decoupled from the mechanical source of turbulence on the ground. However, the evening transition period is non-stationary as heat fluxes decrease over a few hours after sunset so that the aerosol vertical distribution does not respond to surface forcing within an hour [2]. At that part of the day the ceilometer profiles are mostly a result of the turbulence dynamics in the recent periods, therefore, they do not reveal the present ML but its history. That problem is inherent to all remote sensing instruments which use aerosol backscatter to trace the ML but can be overcome if a "true turbulence profiler" is used. As observed, the MLH determined by the Ri method is $\sim 1940 \mathrm{~m}$ which corresponds very well to the aerosol distribution depicted by the ceilometer backscatter signal at the moment of balloon launching (at 13:30 LT that day).

It is also noticeable that the STRAT algorithm plausibly represents the diurnal evolution of the MLH. However, in the time interval from sunrise (6:09 LT) to approximately 10:30 LT, which corresponds to the morning transition period, STRAT misleadingly reports an overhead backscatter gradient (associated with the residual layer) as MLH instead of the one closest to the ground. Similar behaviour is found across all days and seems to be due to the layer attribution technique implemented in STRAT. According to Haeffelin et al. [48] the algorithm reports the strongest, second strongest, and the lowest gradients in backscatter and then, depending on the local time, it constructs a diurnal evolution of its "best estimate" (used here as MLH) which is the lowest gradient during the night and the strongest gradient during the day. Thus, the STRAT method reports abrupt changes in MLH around sunrise and sunset instead of smooth transitions from the nocturnal to convective boundary layer, and vice versa. Possible improvement of layer attributions and representations of the MLH diurnal evolution can be achieved through the use of statistical analysis [67] or graph theory [68].

It can be seen that the overall consistency of the MLHs reported by the Jenoptik algorithm with the observed aerosol distribution and evolution is relatively poorer than the consistency of the STRAT's MLHs. However, Jenoptik outperforms STRAT in the morning transition, although neither method can track the MLH from 8 to $9 \mathrm{LT}$ when the MLH is in the zone of incomplete overlapping. The performance of the Jenoptik method during daytime is much worse and it cannot represent the MLH evolution. The method cannot report MLH from 13 to 17 LT and it significantly underestimates ML depth around noon and in the late afternoon. It should be noted that STRAT also locates these aerosol gradients at intermediate levels (Figure 6) but reports them as the lowest and the second strongest candidates, which are then successfully filtered out by the attribution procedure in the algorithm. This worsened performance of the Jenoptik method is likely to be a result of the immaturity of the outdated version of the algorithm used. Additionally, the Jenoptik method operates in real-time so it is likely to use only the current backscatter profile without taking into account previous measurements. Therefore, 
the signal-to-noise ratio (SNR) will be lower, which may result in poor performance compared to STRAT. Consequently, the poorer daytime performance of the Jenoptik can be attributed to reduced backscatter signal within the increased depth of the MLH (and enlarged volume for aerosol dispersion) and augmented background signal due to the higher sun elevation angle. Data shows the STRAT method also has similar troubles with backscatter gradient detection from $\sim 13: 00$ LT to $\sim 15: 00$ LT when only a few MLHs are reported. However, the process of smoothing incorporated within the algorithm enhances the SNR, enabling the MLH evolution to be tracked against the Jenoptik algorithm.

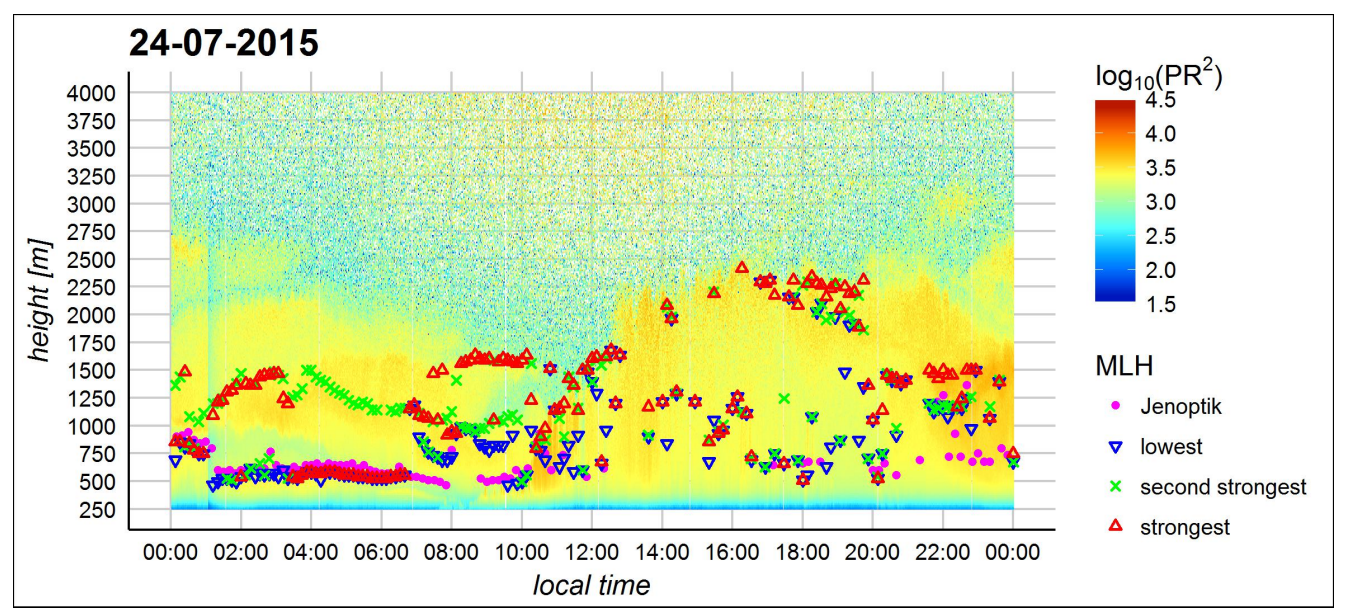

Figure 6. Time-height cross section of the ceilometer's range-corrected backscatter power $\left(\mathrm{PR}^{2}\right.$ in arbitrary units) on 24 July 2015. The MLH calculated by the Jenoptik algorithm (magenta dots) and STRAT's candidates (the strongest gradient—red triangles, the second strongest gradient-green " $x$ " marks, and the lowest gradient-blue upside down triangles) are also shown.

\subsection{Diurnal Evolution of the MLH Determined by Ceilometer-A Statistical Analysis}

To compare the performance of both LiDAR-based algorithms we first make the datasets comparable. Since the Jenoptik algorithm has a 1-min resolution but STRAT's temporal resolution is $10 \mathrm{~min}$, Jenoptik-derived MLHs are averaged in 10-minute intervals. The availability of STRATand Jenoptik-derived MLHs after applying the described procedure is presented in Figure 7. As seen, MLH data availability of both methods show similar patterns related to the diurnal cycle. The STRAT algorithm manages to estimate MLHs in about 70-95\% of the cases but in the afternoon its availability drops to $50-70 \%$ with minimum of $\sim 45 \%$ at 14 LT. In contrast, the Jenoptik method provides MLHs in about $60-85 \%$ of the cases but in the afternoon it hardly reaches even $35-40 \%$ with a minimum of $\sim 15 \%$ at 15 LT. The observed diurnal pattern in MLH availability in both LiDAR-based methods is closely related to decreased SNR due to reduced aerosol concentration (due to increased volume for aerosol dispersion) and increased background signal (due to higher solar radiation) in the afternoon. Neither of the two applied algorithms show a clear atmospheric pressure dependency.
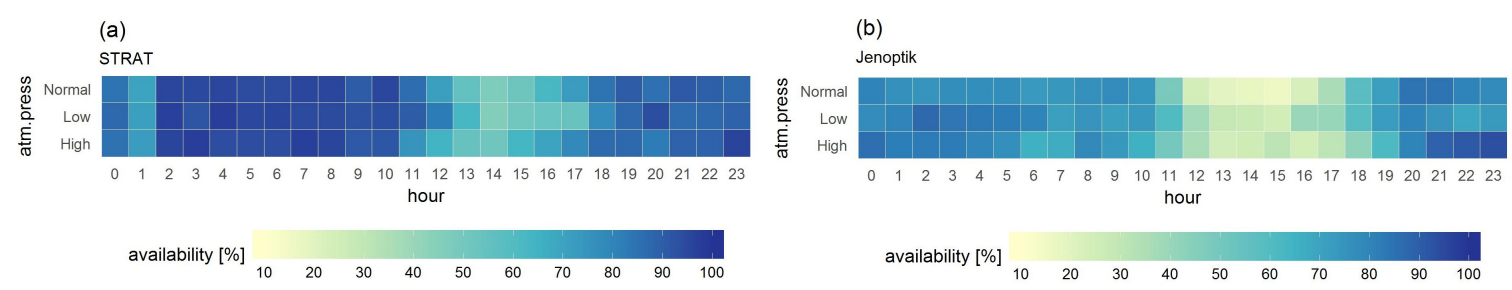

Figure 7. Diurnal evolution of the availability of MLH determined by STRAT (a) and Jenoptik (b) algorithms at "Normal", "Low" and "High" atmospheric pressure in summer of 2015.

The aforementioned features of both LiDAR-based techniques are also visible if all data for the MLH daytime progress are summarised and presented as box-plots (Figure 8). From midnight to 
7 LT STRAT and Jenoptik algorithms provide comparable MLHs and most of the estimated values are in the range of 500-1000 m. However, the Jenoptik also shows several quite large values marked as outliers (most of them in the range 1500-3500 m) which are a result of improper selection of high aerosol layers that cannot be related to the near-ground turbulence. When atmospheric pressure is "Normal" the Jenoptik algorithm also reports a few quite low MLH in the ceilometer's incomplete overlapping zone which should be treated as incorrect values (most likely they are result of multiple scattering). The morning transition is marked by STRAT as an abrupt jump that is a result of its layer attribution criterion, while the Jenoptik represents the transition less steeply. Daytime performance of both algorithms is, thus, easily distinguishable. The MLHs retrieved by Jenoptik are often in the first $1 \mathrm{~km}$ and rarely reach $2 \mathrm{~km}$. As was noted, the algorithm tends to report mid-level gradients that are also marked by STRAT lowest-height and/or second strongest gradients. However, in STRAT these mid-level gradients in the ML are successfully filtered out by the successive layer attribution. The daily maximum of MLH (sometimes more than $2000 \mathrm{~m}$ ) is registered in the late afternoon ( 18:00 LT), a few hours before sunset and, more importantly, during peak car traffic, which can help against excessive concentrations of air pollution. The evening transition is hard to be correctly traced by the LiDAR's backscatter profile as the aerosol signature is more related to turbulent mixing in the past than the current state. Therefore, although showing different behaviours, it is difficult to designate one of the two methods as more reliable. It is worth noting that there are a large number of outliers in the retrieved MLHs by the Jenoptik algorithm; most of them are related to high aerosol layers due to advection or residual layers at night. As seen, both methods report lower daytime MLHs in "Low" atmospheric pressure, especially Jenoptik algorithm, whose estimates do not reach $1 \mathrm{~km}$ in $50 \%$ of cases.

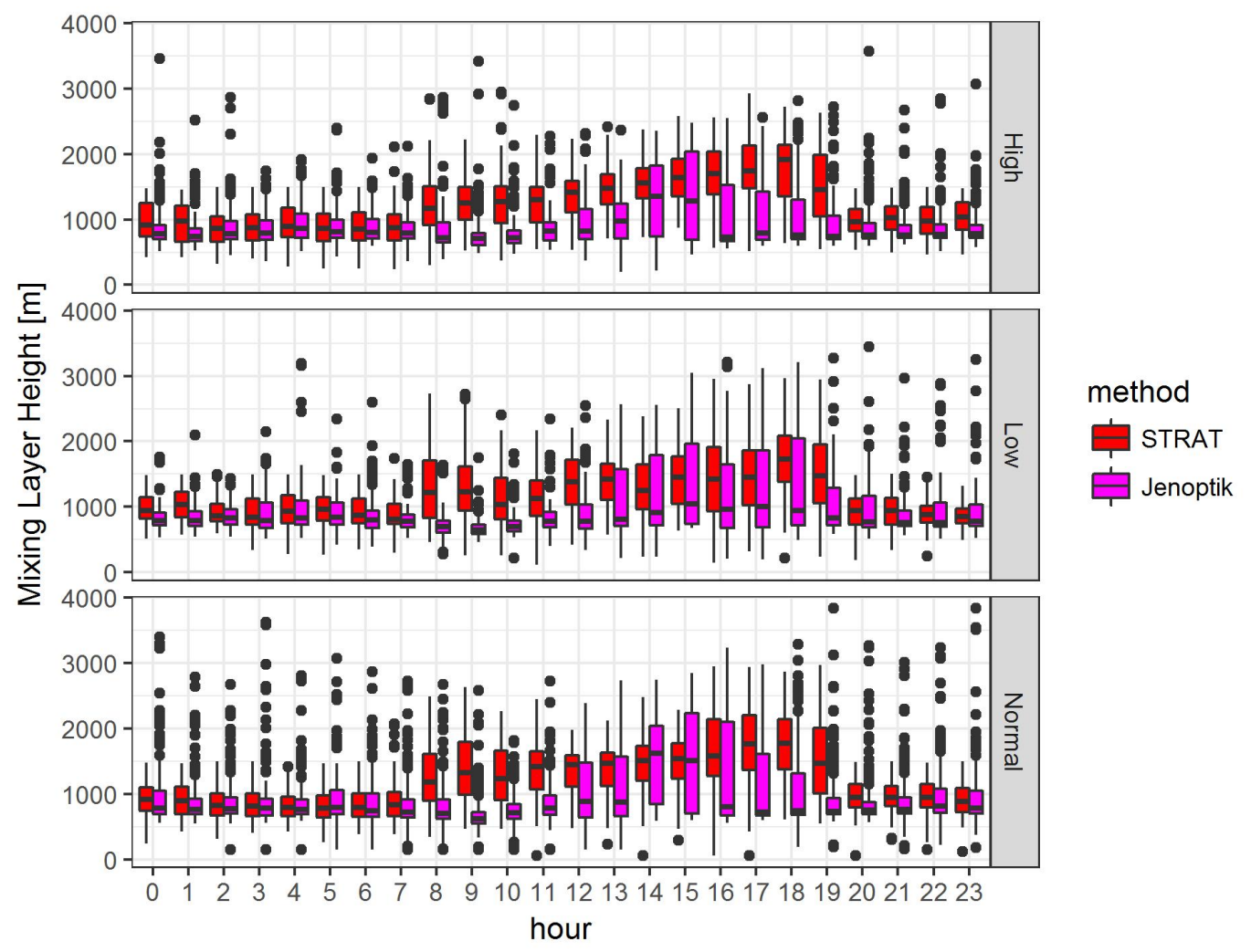

Figure 8. Diurnal cycle of the MLH over Sofia determined by STRAT (red) and Jenoptik (magenta) algorithms as a box and whiskers plot (in Tukey's style) at "High", "Low" and "Normal" atmospheric pressure in summer of 2015. 


\section{Conclusions}

In this paper, MLHs derived by different algorithms over three summer months from radiosonde and ceilometer data were analysed and compared. It was shown that the Richardson and parcel methods produce identical MLHs which indicates that ML is primarily thermally driven while the lapse-rate method underestimates the MLH. It was also found that threshold values for potential temperature higher than $2 \mathrm{~K} / \mathrm{km}$ or smaller than $1 \mathrm{~K} / \mathrm{km}$ deteriorate the agreement of lapse rate with the Richardson and parcel methods. Based on performed comparison against the Richardson method, it was shown that the ceilometer tends to underestimate the MLH. The observed discrepancy was mainly attributed to different land surface types where the instruments are situated and the distance between the sites. Additionally, the proprietary algorithm has difficulty with the low SNR of the ceilometer and frequently cannot report any MLH. In contrast, STRAT handles this better in that it incorporates SNR enhancement. It was shown that the ceilometer-derived aerosol profiles provide consistent with expected MLH information, which can be used to trace the urban MLH dynamics during day. However, the Jenoptik algorithm has difficulty (low availability of reported MLH due to reduced SNR when ML is high) primarily due to the early version of the software used in this work. The hampered tracking of the MLH by the proprietary algorithm may also be a result of the real-time operation on a single profile without making use of the previously collected data. The primary issues of both LiDAR-based techniques were identified as layer attribution, particularly at night and during transition periods when high aerosol layers were mistakenly used by the algorithms. It was underlined that incomplete overlapping of the ceilometer impacts the detection of low MLH at night. Based on the performed statistical analysis it was shown that the STRAT algorithm reconstructs expected MLH dynamics during the day, with maximums in the late afternoon. On the other hand, the Jenoptik method rarely reports MLH values in daytime, which embarrasses the tracking of the MLH diurnal evolution.

Funding: This research and publication costs were funded by the Bulgarian National Science Fund grant number DM 04/1 2016.

Acknowledgments: This study would not be possible without TOPROF_European COST action ES1303 and the advices and recommendations of all TOPROF members. The author is also grateful to NOAA's National Centers for Environmental Information for providing the IGRA. Acknowledgements are due to all contributors to the $\mathrm{R}$ project. The author would also like to thank anonymous readers whose valuable comments and corrections significantly improved paper quality.

Conflicts of Interest: The author declares no conflict of interest.

\section{References}

1. Seibert, P.; Beyrich, F.; Gryning, S.E.; Joffre, S.; Rasmussen, A.; Tercier, P. Review and intercomparison of operational methods for the determination of the mixing height. Atmos. Environ. 2000, 34, 1001-1027. [CrossRef]

2. Momen, M.; Bou-Zeid, E. Analytical reduced models for the non-stationary diabatic atmospheric boundary layer. Bound.-Layer Meteorol. 2017, 164, 383-399. [CrossRef]

3. Schäfer, K.; Emeis, S.; Hoffmann, H.; Jahn, C. Influence of mixing layer height upon air pollution in urban and sub-urban areas. Meteorol. Z. 2006, 15, 647-658. [CrossRef]

4. Schäfer, K.; Wagner, P.; Emeis, S.; Jahn, C.; Muenkel, C.; Suppan, P. Mixing layer height and air pollution levels in urban area. In Proceedings of SPIE-Remote Sensing of Clouds and the Atmosphere XVII; SPIE: Bellingham, WA, USA, 2012; Volume 8534, p. 853409. [CrossRef]

5. Yuan, J.; Bu, L.; Huang, X.; Gao, H.; Sa, R. Particulate Characteristics during a Haze Episode Based on Two Ceilometers with Different Wavelengths. Atmosphere 2016, 7, 20. [CrossRef]

6. Zang, Z.; Wang, W.; Cheng, X.; Yang, B.; Pan, X.; You, W. Effects of Boundary Layer Height on the Model of Ground-Level PM2.5 Concentrations from AOD: Comparison of Stable and Convective Boundary Layer Heights from Different Methods. Atmosphere 2017, 8, 104. [CrossRef] 
7. Geiß, A.; Wiegner, M.; Bonn, B.; Schäfer, K.; Forkel, R.; Schneidemesser, E.v.; Münkel, C.; Chan, K.L.; Nothard, R. Mixing layer height as an indicator for urban air quality? Atmos. Meas. Tech. 2017, 10, 2969-2988. [CrossRef]

8. Mues, A.; Rupakheti, M.; Münkel, C.; Lauer, A.; Bozem, H.; Hoor, P.; Butler, T.; Lawrence, M.G. Investigation of the mixing layer height derived from ceilometer measurements in the Kathmandu Valley and implications for local air quality. Atmos. Chem. Phys. 2017, 17, 8157-8176. [CrossRef]

9. Zeng, S.; Zhang, Y. The Effect of Meteorological Elements on Continuing Heavy Air Pollution: A Case Study in the Chengdu Area during the 2014 Spring Festival. Atmosphere 2017, 8, 71. [CrossRef]

10. Kotthaus, S.; Halios, C.H.; Barlow, J.F.; Grimmond, C. Volume for pollution dispersion: London's atmospheric boundary layer during ClearfLo observed with two ground-based lidar types. Atmos. Environ. 2018, 190, 401-414. [CrossRef]

11. Li, X.X.; Britter, R.E.; Norford, L.K.; Koh, T.Y.; Entekhabi, D. Flow and pollutant transport in urban street canyons of different aspect ratios with ground heating: Large-eddy simulation. Bound.-Layer Meteorol. 2012, 142, 289-304. [CrossRef]

12. Baklanov, A. The mixing height in urban areas-A review. Mix. Heights Invers. Urban Areas COST Action 2002, 715, 9-28.

13. Schäfer, K.; Emeis, S.; Jahn, C.; Münkel, C.; Schrader, S.; Höß, M. New results from continuous mixing layer height monitoring in urban atmosphere. In Proceedings of SPIE—Remote Sensing of Clouds and the Atmosphere XIII; SPIE: Bellingham, WA, USA, 2008; Volume 7107, p. 71070A. [CrossRef]

14. Vishnu, R.; Kumar, Y.B.; Sinha, P.R.; Rao, T.N.; Samuel, E.J.J.; Kumar, P. Comparison of mixing layer heights determined using LiDAR, radiosonde, and numerical weather prediction model at a rural site in southern India. Int. J. Remote Sens. 2017, 38, 6366-6385. [CrossRef]

15. Banks, R.F.; Tiana-Alsina, J.; Rocadenbosch, F.; Baldasano, J.M. Performance evaluation of the boundary-layer height from lidar and the Weather Research and Forecasting model at an urban coastal site in the north-east Iberian Peninsula. Bound.-Layer Meteorol. 2015, 157, 265-292. [CrossRef]

16. Kumer, V.M.; Reuder, J.; Dorninger, M.; Zauner, R.; Grubišić, V. Turbulent kinetic energy estimates from profiling wind LiDAR measurements and their potential for wind energy applications. Renew. Energy 2016, 99, 898-910. [CrossRef]

17. O'Connor, E.J.; Illingworth, A.J.; Brooks, I.M.; Westbrook, C.D.; Hogan, R.J.; Davies, F.; Brooks, B.J. A method for estimating the turbulent kinetic energy dissipation rate from a vertically pointing Doppler lidar, and independent evaluation from balloon-borne in situ measurements. J. Atmos. Ocean. Technol. 2010, 27, 1652-1664. [CrossRef]

18. Schween, J.; Hirsikko, A.; Löhnert, U.; Crewell, S. Mixing-layer height retrieval with ceilometer and Doppler lidar: From case studies to long-term assessment. Atmos. Meas. Tech. 2014, 7, 3685-3704. [CrossRef]

19. Lokoshchenko, M.A. Long-term sodar observations in Moscow and a new approach to potential mixing determination by radiosonde data. J. Atmos. Ocean. Technol. 2002, 19, 1151-1162. [CrossRef]

20. Emeis, S.; Türk, M. Frequency distributions of the mixing height over an urban area from SODAR data. Meteorol. Z. 2004, 13, 361-367. [CrossRef]

21. Stull, R.B. An Introduction to Boundary Layer Meteorology; Springer Science \& Business Media: Berlin, Germany, 1988. [CrossRef]

22. Sicard, M.; Perez, C.; Comeren, A.; Baldasano, J.M.; Rocadenbosch, F. Determination of the mixing layer height from regular lidar measurements in the Barcelona area. In Remote Sensing of Clouds and the Atmosphere VIII; SPIE: Bellingham, WA, USA, 2004; Volume 5235, pp. 505-517. [CrossRef]

23. Cimini, D.; De Angelis, F.; Dupont, J.C.; Pal, S.; Haeffelin, M. Mixing layer height retrievals by multichannel microwave radiometer observations. Atmos. Meas. Tech. 2012, 6, 2941-2951. [CrossRef]

24. Holzworth, G.C. Estimates of mean maximum mixing depths in the contiguous United States. Mon. Weather Rev. 1964, 92, 235-242. [CrossRef]

25. Wang, X.; Wang, K. Estimation of atmospheric mixing layer height from radiosonde data. Atmos. Meas. Tech. 2014, 7, 1701-1709. [CrossRef]

26. Hennemuth, B.; Lammert, A. Determination of the atmospheric boundary layer height from radiosonde and lidar backscatter. Bound.-Layer Meteorol. 2006, 120, 181-200. [CrossRef] 
27. Wiegner, M.; Emeis, S.; Freudenthaler, V.; Heese, B.; Junkermann, W.; Münkel, C.; Schäfer, K.; Seefeldner, M.; Vogt, S. Mixing layer height over Munich, Germany: Variability and comparisons of different methodologies. J. Geophys. Res. Atmos. 2006, 111. [CrossRef]

28. Emeis, S.; Schäfer, K.; Münkel, C. Surface-based remote sensing of the mixing-layer height-A review. Meteorol. Z. 2008, 17, 621-630. [CrossRef] [PubMed]

29. Beyrich, F.; Görsdorf, U. Composing the diurnal cycle of mixing height from simultaneous sodar and wind profiler measurements. Bound.-Layer Meteorol. 1995, 76, 387-394. [CrossRef]

30. Winker, D.M.; Vaughan, M.A.; Omar, A.; Hu, Y.; Powell, K.A.; Liu, Z.; Hunt, W.H.; Young, S.A. Overview of the CALIPSO mission and CALIOP data processing algorithms. J. Atmos. Ocean. Technol. 2009, 26, $2310-2323$. [CrossRef]

31. Kaufman, Y.J.; Tanré, D.; Remer, L.A.; Vermote, E.; Chu, A.; Holben, B. Operational remote sensing of tropospheric aerosol over land from EOS moderate resolution imaging spectroradiometer. J. Geophys. Res. Atmos. 1997, 102, 17051-17067. [CrossRef]

32. Luo, T.; Yuan, R.; Wang, Z. Lidar-based remote sensing of atmospheric boundary layer height over land and ocean. Atmos. Meas. Tech. 2014, 7, 173-182. [CrossRef]

33. Zhang, W.; Guo, J.; Miao, Y.; Liu, H.; Zhang, Y.; Li, Z.; Zhai, P. Planetary boundary layer height from CALIOP compared to radiosonde over China. Atmos. Chem. Phys. 2016, 16, 9951-9963. [CrossRef]

34. Liu, Z.; Mortier, A.; Li, Z.; Hou, W.; Goloub, P.; Lv, Y.; Chen, X.; Li, D.; Li, K.; Xie, Y. Improving Daytime Planetary Boundary Layer Height Determination from CALIOP: Validation Based on Ground-Based Lidar Station. Adv. Meteorol. 2017, 2017, 5759074. [CrossRef]

35. Feng, X.; Wu, B.; Yan, N. A method for deriving the boundary layer mixing height from modis atmospheric profile data. Atmosphere 2015, 6, 1346-1361. [CrossRef]

36. Sokolovskiy, S.; Kuo, Y.H.; Rocken, C.; Schreiner, W.; Hunt, D.; Anthes, R. Monitoring the atmospheric boundary layer by GPS radio occultation signals recorded in the open-loop mode. Geophys. Res. Lett. 2006, 33. [CrossRef]

37. Guo, P.; Kuo, Y.H.; Sokolovskiy, S.; Lenschow, D. Estimating atmospheric boundary layer depth using COSMIC radio occultation data. J. Atmos. Sci. 2011, 68, 1703-1713. [CrossRef]

38. García-Franco, J.; Stremme, W.; Bezanilla, A.; Ruiz-Angulo, A.; Grutter, M. Variability of the Mixed-Layer Height Over Mexico City. Bound.-Layer Meteorol. 2018, 167, 493-507. [CrossRef]

39. Knepp, T.N.; Szykman, J.J.; Long, R.; Duvall, R.M.; Krug, J.; Beaver, M.; Cavender, K.; Kronmiller, K.; Wheeler, M.; Delgado, R.; et al. Assessment of mixed-layer height estimation from single-wavelength ceilometer profiles. Atmos. Meas. Tech. 2017, 10, 3963. [CrossRef] [PubMed]

40. Peng, J.; Grimmond, C.S.B.; Fu, X.; Chang, Y.; Zhang, G.; Guo, J.; Tang, C.; Gao, J.; Xu, X.; Tan, J. Ceilometer-Based Analysis of Shanghai's Boundary Layer Height (under Rain-and Fog-Free Conditions). J. Atmos. Ocean. Technol. 2017, 34, 749-764. [CrossRef]

41. Nemuc, A.; Nicolae, D.; Talianu, C.; Carstea, E.; Radu, C. Dynamic of the lower troposphere from multiwavelength LIDAR measurements. Roman. Rep. Phys. 2009, 61, 313-323.

42. Ungureanu, I.; Stefan, S.; Nicolae, D. Investigation of the cloud cover and planetary boundary layer (PBL) characteristics using ceilometer CL-31. Roman. Rep. Phys. 2010, 62, 396-404.

43. Wang, W.; Gong, W.; Mao, F.; Pan, Z. An improved iterative fitting method to estimate nocturnal residual layer height. Atmosphere 2016, 7, 106. [CrossRef]

44. Li, H.; Yang, Y.; Hu, X.M.; Huang, Z.; Wang, G.; Zhang, B. Application of Convective Condensation Level Limiter in Convective Boundary Layer Height Retrieval Based on Lidar Data. Atmosphere 2017, 8, 79. [CrossRef]

45. Caicedo, V.; Rappenglück, B.; Lefer, B.; Morris, G.; Toledo, D.; Delgado, R. Comparison of aerosol lidar retrieval methods for boundary layer height detection using ceilometer aerosol backscatter data. Atmos. Meas. Tech. 2017, 10, 1609-1622. [CrossRef]

46. Illingworth, A. TOPROF (COST Action ES1303)-Towards Operational Ground Based Profiling with Ceilometers, Doppler Lidars and Microwave Radiometers for Improving Weather Forecasts. Available online: http:/ / www.toprof.imaa.cnr.it/ (accessed on 30 November 2018).

47. EUMETNET Composite Observing System-E-PROFILE. Available online: http://eumetnet.eu/activities / observations-programme/current-activities/e-profile/ (accessed on 30 November 2018). 
48. Haeffelin, M.; Angelini, F.; Morille, Y.; Martucci, G.; Frey, S.; Gobbi, G.; Lolli, S.; O'dowd, C.; Sauvage, L.; Xueref-Rémy, I.; et al. Evaluation of mixing-height retrievals from automatic profiling lidars and ceilometers in view of future integrated networks in Europe. Bound.-Layer Meteorol. 2012, 143, 49-75. [CrossRef]

49. Münkel, C.; Eresmaa, N.; Räsänen, J.; Karppinen, A. Retrieval of mixing height and dust concentration with lidar ceilometer. Bound.-Layer Meteorol. 2007, 124, 117-128. [CrossRef]

50. Uzan, L.; Egert, S.; Alpert, P. Ceilometer evaluation of the eastern Mediterranean summer boundary layer height-First study of two Israeli sites. Atmos. Meas. Tech. 2016, 9, 4387-4398. [CrossRef]

51. Stachlewska, I.; Piądłowski, M.; Migacz, S.; Szkop, A.; Zielińska, A.; Swaczyna, P. Ceilometer observations of the boundary layer over Warsaw, Poland. Acta Geophys. 2012, 60, 1386-1412. [CrossRef]

52. Morille, Y.; Haeffelin, M.; Drobinski, P.; Pelon, J. STRAT: An automated algorithm to retrieve the vertical structure of the atmosphere from single-channel lidar data. J. Atmos. Ocean. Technol. 2007, 24, 761-775. [CrossRef]

53. Poltera, Y.; Martucci, G.; Collaud Coen, M.; Hervo, M.; Emmenegger, L.; Henne, S.; Brunner, D.; Haefele, A. PathfinderTURB: An automatic boundary layer algorithm. Development, validation and application to study the impact on in-situ measurements at the Jungfraujoch. Atmos. Chem. Phys. Discuss. 2017. [CrossRef]

54. Kotthaus, S.; Grimmond, C.S.B. Atmospheric boundary-layer characteristics from ceilometer measurements. Part 1: A new method to track mixed layer height and classify clouds. Q. J. R. Meteorol. Soc. 2018, 144, 1525-1538. [CrossRef]

55. Griffiths, A.; Parkes, S.; Chambers, S.; McCabe, M.; Williams, A. Improved mixing height monitoring through a combination of lidar and radon measurements. Atmos. Meas. Tech. 2013, 6, 207-218. [CrossRef]

56. Galeriu, D.; Melintescu, A.; Stochioiu, A.; Nicolae, D.; Balin, I. Radon, as a tracer for mixing height dynamicsAn overview and RADO perspectives. Roman. Rep. Phys. 2011, 63, 115-127.

57. Heese, B.; Flentje, H.; Althausen, D.; Ansmann, A.; Frey, S. Ceilometer lidar comparison: Backscatter coefficient retrieval and signal-to-noise ratio determination. Atmos. Meas. Tech. 2010, 3, 1763-1770. [CrossRef]

58. Jenoptik. Cloud Height Meter CHM 15k-User Manual; JENOPTIK Laser, Optical Systems GmbH: Jena, Germany, 2009.

59. Durre, I.; Vose, R.S.; Wuertz, D.B. Overview of the integrated global radiosonde archive. J. Clim. 2006, 19, 53-68. [CrossRef]

60. De Haij, M.; Wauben, W.; Baltink, H.K. Continuous Mixing Layer Height Determination Using the LD-40 Ceilometer: A Feasibility Study; Royal Netherlands Meteorological Institute (KNMI): De Bilt, The Netherlands, 2007.

61. Vogelezang, D.; Holtslag, A. Evaluation and model impacts of alternative boundary-layer height formulations. Bound.-Layer Meteorol. 1996, 81, 245-269. [CrossRef]

62. Menut, L.; Flamant, C.; Pelon, J.; Flamant, P.H. Urban boundary-layer height determination from lidar measurements over the Paris area. Appl. Opt. 1999, 38, 945-954. [CrossRef] [PubMed]

63. Sicard, M.; Pérez, C.; Rocadenbosch, F.; Baldasano, J.; García-Vizcaino, D. Mixed-layer depth determination in the Barcelona coastal area from regular lidar measurements: Methods, results and limitations. Bound.-Layer Meteorol. 2006, 119, 135-157. [CrossRef]

64. Holzworth, G.C. Mixing depths, wind speeds and air pollution potential for selected locations in the United States. J. Appl. Meteorol. 1967, 6, 1039-1044. [CrossRef]

65. Garrett, A. Comparison of Observed Mixed-Layer Depths to Model Estimates Using Observed Temperatures and Winds, and MOS Forecasts. J. Appl. Meteorol. 1981, 20, 1277-1283. [CrossRef]

66. Dang, R.; Li, H.; Liu, Z.; Yang, Y. Statistical analysis of relationship between daytime Lidar-derived planetary boundary layer height and relevant atmospheric variables in the semiarid region in Northwest China. Adv. Meteorol. 2016, 2016. [CrossRef]

67. Lotteraner, C.; Piringer, M. Mixing-height time series from operational ceilometer aerosol-layer heights. Bound.-Layer Meteorol. 2016, 161, 265-287. [CrossRef]

68. de Bruine, M.; Apituley, A.; Donovan, D.P.; Klein Baltink, H.; de Haij, M.J. Pathfinder: Applying graph theory to consistent tracking of daytime mixed layer height with backscatter lidar. Atmos. Meas. Tech. 2017, 10, 1893-1909. [CrossRef]

(C) 2019 by the author. Licensee MDPI, Basel, Switzerland. This article is an open access article distributed under the terms and conditions of the Creative Commons Attribution (CC BY) license (http://creativecommons.org/licenses/by/4.0/). 